\title{
Clinical Study of Patients with Oral Lichenoid Processes Attending Khanzad Specialized Teaching Center and Erbil Dermatology Teaching Center \\ Vaman Jalal Hamza (BDS) ${ }^{1}$, Ali Fakhree Alzubaidee (FFDRCS (Irel), FDSRCS (Eng), FDSRCPS (Glas) $)^{2}$ and Dindar Sharif Qurtas (MBChB, MD, $\left.\mathrm{PhD}\right)^{3}$ Abstract
}

Background: Lichen planus is a common chronic inflammatory disease of the skin and mucous membranes. Oral Lichenoid Reactions (OLRs) comprise a group of lesions with different causative factors such as systemic medication, dental restorative materials, foods, or flavoring agents. Pathologists often group these conditions under the umbrella term of 'lichenoid processes'.

Objective: To provide prevalence and demographic distribution of Oral Lichen Planus (OLP) and OLR among a sample of patients.

Patients and Methods: This cross-sectional study was conducted in the Khanzad Teaching Center and Erbil Dermatology Teaching Center. The diagnosis of patients with OLP and OLR were suspected clinically and histopathologically confirmed. Eighty patients of OLP and OLR have been enrolled from both centers. Detailed case histories and clinical presentations were recorded through a questionnaire.

Results: Among those patients, 60 (75.0\%) were diagnosed as OLP, and 20 (25.0\%) patients diagnosed as OLR. Their mean age \pm SD was $49.01 \pm 11.22$ years. Bilateral buccal mucosa $(83.8 \%)$ was the most affected sites in both groups. The most common clinical types were reticular $(90 \%)$, and erosive $(33.8 \%)$. Only 7 patients $(8.8 \%)$ had an associated skin lichen planus (SLP).

Conclusion: The present study revealed that the buccal mucosa was the most affected site, followed by the tongue and palate. The reticular type was the most common affected type followed by the erosive type.

Keywords: Oral lichenoid processes, oral lichen planus, oral lichenoid reactions, skin lichen planus

Corresponding Author: immortal.vjh25@gmail.com

Received: $28^{\text {th }}$ June 2020

Accepted: $28^{\text {th }}$ August 2020

DOI:https://doi.org/10.26505/DJM.19025460628

\footnotetext{
${ }^{1}$ Khanzad Specialized Teaching Center-Candidate of Oral and Maxillofacial Medicine - Erbil- Iraq ${ }^{2}$ Professor and Consultant of at Kurdistan Board of Medical Specialties-Head of Council of Dental Specialties-ErbilIraq ${ }^{3}$ Head of Dermatology Unit- Hawler Medical University- Erbil- Iraq
} 


\section{Introduction}

Lichen planus is a common chronic inflammatory disease of skin and mucous membranes. Although in most patients the features are characteristic, they are varied and not very specific. A number of other diseases appear similar or identical. This is confusing both clinically and terminologically. Pathologists often group these conditions under the umbrella term of 'lichenoid processes' based on their histopathology, but in clinical parlance 'lichenoid' is usually reserved for conditions that mimic lichen planus clinically[1]. Oral lichen planus (OLP) was first discovered clinically by Wilson in 1869[2]. The OLP is a chronic inflammatory disease that affects the stratified squamous epithelium. It involves the oral and genital mucous membranes; skin; nails and scalp, furthermore esophageal mucosa, larynx, and conjunctivae[3]. Most of affected patients present with only oral lesions, which are sometimes referred to as "isolated" OLP $[2,4]$. Cutaneous lichen planus (CLP) most commonly affects the flexor surfaces of the limbs and presents as small itchy violaceous papules in middle-aged adults. "Pruritic, Purple, Polygonal, Planar, Papules, and Plaques" are the traditional 6 "P's" of LP[5]. The distribution of the disease in the general population is $0.1-4 \%$ [6].OLP shows a female predilection and mainly affects adult patients between their fifth and sixth decades of life[7,8]. Although the precise cause of OLP is unknown, multiple factors are considered to be involved, which may include genetic, psychological, and infectious factors. Some of these factors may act as causal agents, while others may trigger the process $[9,10]$.

Oral Lichenoid Reactions (OLRs) comprise a group of lesions with different causative factors such as systemic medication, dental restorative materials, foods, or flavoring agents[11,12]. Many materials used in dental restorations treatments in the oral cavity have been identified as triggering elements for OLRs, including silver amalgam, gold, cobalt, palladium, chromium, and even nonmetals such as epoxy resins (composite) and prolonged use of denture[7,10,13]. Oral lichenoid drug reactions may be caused by systemic drugs including NSAIDs, betablockers, sulfonylureas, some angiotensinconverting enzyme (ACE) inhibitors, some antimalarials, contact allergens including toothpaste flavorings, especially cinnamates[14].

Epidemiological pieces of evidence from various studies worldwide strongly suggest that the hepatitis $\mathrm{C}$ virus (HCV) may be a causative factor in OLP $[15,16]$. Generally, OLP pathogenesis is T cell-mediated chronic inflammatory disease affecting mucosal lining and skin. The inflammatory process is a type IV hypersensitivity reaction to various antigens[7,17].Clinical pres $\neg$ entation have wide spectrum variation from asymptomatic white keratotic lesions to painful erosions and ulcerations.18 Six clinical types of lichen planus are present which include: reticular, popular, plaque-like, erosive, atrophic and, bullous[19]. The most common types are reticular and erosive forms[4]. Intraorally, the most commonly involved sites are buccal mucosa, tongue, and gingiva while the other 
areas like mucosa of the palate and floor of the mouth are rarely affected[4]. Oral pigmentation has also been observed in some patients with lichen planus (lichen planus pigmentosus)[20]. Lichen planus may be a result of melanin drop-out, especially in persons with pigmented skin.21 Histopathological characteristics of OLP include dense subepithelial lymphocytic infiltrate, lymphocytic invasion of epithelium, and hydropic degeneration of basal keratinocytes[19].

One of the most significant complications concerning the progression and prognosis of OLP is the development of oral squamous cell carcinoma (OSCC), with a range of malignant transformation of $0.4-5.3 \%, 22$ which led the World Health Organization (WHO) to consider OLP as a potentially malignant disorder[23]. Treatment of OLP is symptomatic, the asymptomatic forms usually need no treatment. Corticosteroids are the most commonly used drugs. Other drugs, like calcineurin inhibitors, azathioprine, mycophenolate mofetil, retinoids, dapsone, and hydroxychloroquine can be used in recalcitrant cases[24]. The aim of this study is to provide prevalence and demographic distribution of OLP and OLR among a sample of patients.

\section{Patients and Methods}

This cross-sectional study was conducted in the Khanzad Teaching Center and Erbil Dermatology Teaching Center. The study protocol was approved by the ethical committee at the Kurdistan Board for Medical Specialties, also have been discussed and approved by the scientific comittee of the oral and maxillofacial medicine in the
Kurdistan Board for Medical Specialists before starting the work. Informed consent was signed by the patients after a complete explanation of the purpose of the study. No therapeutic intervention was made and the patient's data were kept confidential. No costs were inflicted on the patients for the laboratory tests. The diagnosis of patients with OLP and OLR was suspected clinically and histopathologically confirmed. The diagnostic criteria proposed by van der Meij et al (2003), which is based on the clinical and histopathologic definition of OLP by the WHO were used to identify the OLP cases. Eighty patients of OLP have been enrolled from both centers. Detailed case histories and clinical presentations were recorded through a questionnaire. The questionnaire was including clinical data about age, gender, systemic disease, medications, amalgam, and other types of restorations, duration, and concomitant skin lesion, clinical presentations of the type and site of the OLP and skin lichen planus, and the presence of pigmentation have been recorded. Furthermore, viral screening of Hepatitis C has been done to correlate the relation between OLP and Hepatitis C virus. Exclusion criteria were including any patient that diagnosed with only clinically or nonwilling patients and refuse to undergo a biopsy procedure.

\section{Statistical analysis}

Data were analyzed using the Statistical Package for Social Sciences (SPSS, version 22). Chi-square test of association was used to compare proportions. Fisher's exact test was used when the expected count of more than $20 \%$ of the cells of the table was less 
than 5. A p-value of $\leq 0.05$ was considered statistically significant.

\section{Results}

Eighty patients with oral lichen planus and oral lichenoid lesion were included in the study. Their mean age \pm SD was $49.01 \pm$
11.22 years. The age range was 22 to 80 years, and the median age was 49.5 years. Table (1) shows that one-third of the patients were aged 40-49 years, and another one third were aged 50-59 years. More than two thirds $(68.8 \%)$ of the sample were females.

Table (1): Age and gender distribution

\begin{tabular}{||c||c||c||}
\hline & No. & (\%) \\
\hline \hline Age (years) & & $(16.3)$ \\
\hline \hline 440 & 13 & $(33.8)$ \\
\hline \hline $50-49$ & 27 & $(33.8)$ \\
\hline \hline$\geq 60$ & 27 & $(16.3)$ \\
\hline \hline Gender & 13 & \\
\hline \hline Male & & $(31.3)$ \\
\hline \hline Female & 55 & $(68.8)$ \\
\hline \hline Total & 80 & $(100.0)$ \\
\hline
\end{tabular}

Table (2) shows that the most common sites in the oral cavity affected were as follows: bilateral buccal (83.8\%), tongue (30\%), palate (13.8\%), and gingiva (11.3), in addition to the other sites that are mentioned in the table. The most common clinical types were reticular $(90 \%)$, and erosive $(33.8 \%)$. Only 7 patients $(8.8 \%)$ had an associated skin lichen planus (SLP) as presented in Table (2) which shows that the lesion of 2 out of the 7 patients $(28.6 \%)$ was in the upper and lower limbs. Other sites affected are mentioned in Table(2). The most common type of SLP was the papular $(57.1 \%)$. The table shows also that $72.5 \%$ of the patients had more than 1 type of OLP/patient, and $48.8 \%$ had more than 1 site affected.

Table (2): Sites and types of the oral LP and the skin LP

\begin{tabular}{|l||c|c||}
\hline & No. & \% \\
\hline \hline Clinical sites of OLP $(\mathbf{n}=\mathbf{8 0})$ & & \\
\hline \hline Bilateral buccal & 67 & $(83.8)$ \\
\hline \hline Tongue & 24 & $(30.0)$ \\
\hline \hline Palate & 11 & $(13.8)$ \\
\hline \hline Left buccal mucosa & 9 & $(11.3)$ \\
\hline \hline Labial mucosa & 7 & $(10.0)$ \\
\hline \hline Lip & 7 & $(8.8)$ \\
\hline \hline Right buccal mucosa & 5 & $(8.8)$ \\
\hline \hline Floor of mouth & 4 & $(6.3)$ \\
\hline \hline Clinical types of OLP $(\mathbf{n}=\mathbf{8 0})$ & & $(5.0)$ \\
\hline Reticular & 72 & $(90.0)$ \\
\hline \hline Erosive & 27 & $(33.8)$ \\
\hline \hline Atrophic & 18 & $(25.0)$ \\
\hline \hline Plaque & 7 & $(8.8)$ \\
\hline \hline D gingivitis & 5 & $(6.3)$ \\
\hline \hline Bullous & & \\
\hline
\end{tabular}




\begin{tabular}{|l||c||c||}
\hline Prevalence of skin LP $(\mathbf{n}=\mathbf{8 0})$ & & \\
\hline \hline Not present & 73 & $(91.3)$ \\
\hline \hline Present & & $(8.8)$ \\
\hline Site of SLP $(\mathbf{n}=\mathbf{7})$ & 2 & $(28.6)$ \\
\hline Upper limb and Lower limb & 1 & $(14.3)$ \\
\hline \hline Upper limb, lower limb, scalp and genital & 1 & $(14.3)$ \\
\hline \hline Scalp & 1 & $(14.3)$ \\
\hline \hline Genital limb & 1 & $(14.3)$ \\
\hline \hline $\begin{array}{l}\text { Upper limb, Lower limb, abdomen, back and } \\
\text { genital }\end{array}$ & 1 & $(14.3)$ \\
\hline Type of SLP (n=7) & & \\
\hline Papular & 4 & $(57.1)$ \\
\hline \hline Annular, atrophic popular & 1 & $(14.3)$ \\
\hline \hline Atrophic & 1 & $(14.3)$ \\
\hline \hline Follicular & $58.3)$ \\
\hline \hline No. of type and sites per patient (n= 80) & 39 & $(42.5)$ \\
\hline More than 1 type of OLP/patient & 60 & $(75.0)$ \\
\hline \hline More than 1 site of OLP/patient & 20 & $(25.0)$ \\
\hline \hline Diagnosis (n = 80)
\end{tabular}

Out of the 80 patients, $65(81.3 \%)$ had symptomatic lesions, out of 80 patients $(12.5 \%)$ have been associated with pigmentation and (22.5\%) had amalgam restorations. Also $22(27.5 \%)$ had systemic disease, mainly hypertension (15 out of 22) and diabetes (12 out of 22). Other diseases and habits are presented in Table (3). Both
OLP and OLR shared the same distribution in the clinical presentations, age and gender. In OLR patients (10 out of 20 patients were taking medications that cause OLR mainly metformin, and 10 out of 20 patients had related amalgam filling adjacent to the lesion).

Table (3): Systemic diseases, medications and habits

\begin{tabular}{|c|c|c|c|}
\hline & $\overline{\mathbf{N}}$ & No. & $(\%)$ \\
\hline \multicolumn{4}{|l|}{ Habits } \\
\hline Smoking & 80 & 8 & (10.0) \\
\hline Alcohol & 80 & $\overline{5}$ & $(6.3)$ \\
\hline Systemic diseases & 80 & 22 & 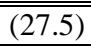 \\
\hline \multicolumn{4}{|l|}{ Type of diseases } \\
\hline Hypertension & 22 & 15 & $\overline{(268.2)}$ \\
\hline Diabetes & 22 & 12 & $\overline{(54.5)}$ \\
\hline Hepatitis C & 80 & 0 & $(0.0)$ \\
\hline Medication causing lichenoid lesion & 80 & 10 & (12.5) \\
\hline \multicolumn{4}{|l|}{ Types of medications } \\
\hline Metformin & 10 & 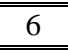 & $\begin{array}{l}(60.0) \\
\end{array}$ \\
\hline Carbamazepine & 10 & 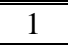 & $(10.0)$ \\
\hline Atenolol & 10 & 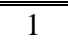 & (10.0) \\
\hline Furosemide & 10 & 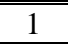 & $(10.0)$ \\
\hline Metformin and enalapril & 10 & 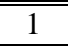 & $(10.0)$ \\
\hline
\end{tabular}


The prevalence of each type of OLP and OLR was calculated in each category of age, gender, amalgam, smoking, alcohol, hypertension, and diabetes, as evident in Table (4). Results showed no significant

Table (4): Prevalence of types of OLP and OLR by age, gender, related to amalgam filling, smoking, alcohol, systemic diseases and related drugs

\begin{tabular}{|c|c|c|c|c|c|c|c|}
\hline & $\mathbf{N}$ & Reticular & Erosive & Atrophic & Plaque & Bullos & D. gingivitis \\
\hline & & No. $(\%)$ & No. $(\%)$ & No. (\%) & No. $(\%)$ & No. $(\%)$ & No. $(\%)$ \\
\hline \multicolumn{8}{|l|}{ Age } \\
\hline$<440$ & 13 & $13(100)$ & $3(23.1)$ & $3(23.1)$ & $2(15.4)$ & $0(0.0)$ & (0(0.0) \\
\hline 40-49 & 27 & 23(85.2) & $\begin{array}{l}11(40.7) \\
\end{array}$ & $3(11.1)$ & $9(33.3)$ & $2(7.4)$ & $2(7.4)$ \\
\hline $\begin{array}{l}50-59 \\
\end{array}$ & 27 & $24(88.9)$ & $7(25.9)$ & $10(37.0)$ & $5(18.5)$ & $2(7.4)$ & $3(11.1)$ \\
\hline$\geq 60$ & 13 & $12(92.3)$ & $6(46.2)$ & $4(30.8)$ & $2(15.4)$ & $1(7.7)$ & $2(15.4)$ \\
\hline P-value & & "0.709* & $0.451 *$ & "0.143* & $0.482 *$ & $>0.999^{*}$ & "0.742* \\
\hline \multicolumn{8}{|l|}{ Gender } \\
\hline Male & 25 & $23(92.0)$ & $7(28.0)$ & $\begin{array}{l}4(16.0) \\
\end{array}$ & $7(28.0)$ & $0(0.0)$ & $0(0.0)$ \\
\hline $\begin{array}{l}\text { Female } \\
\end{array}$ & 55 & 49(89.1) & $20(36.4)$ & $\begin{array}{l}16(29.1) \\
\end{array}$ & $\begin{array}{l}11(20.0) \\
\end{array}$ & $5(9.1)$ & $7(12.7)$ \\
\hline p value & & $>0.999^{*}$ & 0.463 & 0.210 & 0.427 & 0.318 & 0.092 \\
\hline \multicolumn{8}{|c|}{ Amalgam } \\
\hline No & 62 & 55(88.7) & $21(33.9)$ & $15(24.2)$ & $14(22.6)$ & $5(8.1)$ & $7(11.3)$ \\
\hline Yes & 18 & $17(94.4)$ & 6 6(33.3) & $5(27.8)$ & 4 4(22.2) & $0(0.0)$ & $0(0.0)$ \\
\hline p value & & $\begin{array}{c}0.676^{*} \\
\end{array}$ & 0.966 & $0.763^{*}$ & $>0.999^{*}$ & $0.582)$ & $0.340^{*}$ \\
\hline \multicolumn{8}{|l|}{ Smoking } \\
\hline No & 72 & $65(90.3)$ & $25(34.7)$ & $17(23.6)$ & $16(22.2)$ & (5(6.9) & $7(9.7)$ \\
\hline Yes & 8 & $\begin{array}{l}7(87.5) \\
\end{array}$ & $2(25.0)$ & 3 3(37.5) & $2(25.0)$ & $\begin{array}{l}0(0.0) \\
\end{array}$ & $0(0.0)$ \\
\hline p value & & $0.587 *$ & 0.710 & $0.405^{*}$ & $>0.999$ & 0.999* & 0.999* \\
\hline \multicolumn{8}{|l|}{ Alcohol } \\
\hline No & 75 & 6 68(90.7) & $26(34.7)$ & $20(26.7)$ & 15 15(20.0) & (5(6.7) & $7(9.3)$ \\
\hline Yes & 5 & $\begin{array}{l}4(80.0) \\
\end{array}$ & $\begin{array}{l}1(20.0) \\
\end{array}$ & $\begin{array}{l}0(0.0) \\
\end{array}$ & $\begin{array}{l}3(60.0) \\
\end{array}$ & $\begin{array}{l}0(0.0) \\
\end{array}$ & $\begin{array}{l}0(0.0) \\
\end{array}$ \\
\hline$\overline{p \text { p value }}$ & & $0.418^{*}$ & $0.658^{*}$ & $0.324 *$ & $0.072 *$ & $>0.999 *$ & $>0.999 *$ \\
\hline \multicolumn{8}{|c|}{$\begin{array}{l}\text { Systemic Diseases } \\
\text { on drugs causing } \\
\text { OLR: }\end{array}$} \\
\hline \multicolumn{8}{|c|}{ Hypertension } \\
\hline No & 7 & $\begin{array}{l}5(71.4) \\
\end{array}$ & $2(28.6)$ & $1(14.3)$ & $3(42.9)$ & $2(28.6)$ & $1(14.3)$ \\
\hline Yes & 15 & $14(93.3)$ & $8(53.3)$ & $5(33.3)$ & $2(13.3)$ & $2(13.3)$ & $2(13.3)$ \\
\hline p value & & 0.227 & $0.381 *$ & $0.616^{*}$ & $0.274 *$ & $0.565^{*}$ & $>0.999 *$ \\
\hline \multicolumn{8}{|l|}{ Diabetes } \\
\hline No & 10 & $\begin{array}{l}9(90.0) \\
\end{array}$ & $7 \overline{7(70.0)}$ & $\overline{~ 1(10.0)}$ & $2(20.0)$ & $2(20.0)$ & $2(20.0)$ \\
\hline Yes & 12 & $10(83.3)$ & $3(25.0)$ & $5(41.7)$ & $3(25.0)$ & $2(16.7)$ & $1(8.3)$ \\
\hline p value & & $>0.999^{*}$ & 0.084* & 0.162 & $>0.999^{*}$ & $>0.999^{*}$ & $0.571 *$ \\
\hline
\end{tabular}

*By Fisher's exact test (note that the other p values, with no asterisk, were calculated by the Chi square test)

association between the prevalence of types of LP (reticular, erosive, atrophic, plaque, bullous, and D. gingivitis) and the abovementioned variables (all the p-values were > 0.05 ). 


\section{Discussion}

In the current study, there were many similarities and some dissimilarities in clinical features, and demography of oral lichenoid processes (OLP and OLR) with those reported previously. In both groups the lesion was more prevalent in the third and fourth decade of life, their mean age \pm SD was $49.01 \pm 11.22$ years. The age range was 22 to 80 years, and the median age was 49.5 years, which agrees to other reports like in China (56.7 years), UK (52.0 years), and Spain (56.4 years)[23,26,27]. Was also in accordance to studies in Brazil, Sweden, Italy, and Iran (Mashad)[4,18]. In the current study in both groups, there was female predilection over male in a way that more than two-third of the affected patients were females which were in concordance with the majority of the studies where it varied from $1,6: 1[28]$ to $3.3: 1[29]$. Which is in accordance with studies performed in Brazil, China, and Iran (Mashhad) [4,18,27]. However, two studies have shown that both sexes were almost equally affected[30,31].

For both groups, the buccal mucosa was the most common site affected in the current study, which was similar to the findings of previous studies[4,18,26,27,32,33,34] Sites like the palate and floor of the mouth are usually affected in less than $5 \%$ of the cases $[18,20,21,22,26]$ which is a disagreement with the current study that palatal involvement was the third most common site affected, and $48.8 \%$ had more than 1 site of OLP/patient. Patients with more than one oral site were reported in buccal mucosa concomitant with gingiva. Single lesion on the gingiva, palate and floor of the mouth was rare, whereas these sites were involved in concomitant with other sites like buccal mucosa or tongue, or the lesions of OLP affect multiple oral sites, which is consistent with other studies[4,27,35].

Regarding types in both groups, the most common types were reticular and erosive types, similar results were reported by other studies [19,27,36,35]. Also, $72.5 \%$ of the patients had more than 1 type, which was concomitant with other studies[36,37].

Skin lesions of lichen planus appear before, or arise at the same time with an oral lesion or appear after the development of the oral lesion and it is documented that $20-34 \%$ of the patients with oral lesion had also skin LP.19 The most common type of SLP was papular $(57.1 \%)$, which is higher than it was done by Pakfetrat et al study (15.5\%)[17]. This might have been due to the selective referral of patients to our departments.

Regarding the symptoms in both groups, $81.3 \%$ of patients were symptomatic, described as discomfort, burning sensation, pain and difficulty in eating, similar to the studies on Indian [35], Brazilian[4], and Chinese population[27].

About the systemic disease $(27.5 \%)$ had systemic disease, mainly hypertension $12 \%$ and diabetes $9 \%$. Moreover, the incidence of these systemic diseases was lower than the previous reports[18,38]. Regarding the medications that may cause the oral lichenoid reaction, $(12.5 \%)$ had a history or they are on medication intake, mainly metformin, these medications are already known to contribute in the pathogenesis of OLR[39]. 
About the patients with OLR that associated with amalgam filling, 10 out of 20 patients had an amalgam filling adjacent to the lesion, which is in accordance with studies that reported the association of allergic reactions and dental restorative materials[40,41].

Regarding pigmentation in this study, in both groups 10 patients had pigmentation. The most common site of pigmentation was buccal mucosa, the nature of pigmentation was diffuse or in patches, brown to black in color, also similar findings were observed in some Indian studies[42 ]. This may be due to racial factors.

In this study no patient recorded to be $\mathrm{HCV}$ infection positive, this is contrary to previous epidemiological data, which suggest that LP may be associated significantly with $\mathrm{HCV}$ infection in various parts of the world with the presence of geographical difference. This difference may be a clue that OLP in the current sample is not caused, triggered, or associated with HCV infection[43].

Smoking and alcohol drinking was not a common finding among patients in the current study since $(90 \%)$ were non-smokers and this is similar to the results reported[18,19,29]. The great majority $(93.75 \%)$ of the patients were not drinkers which were also reported in other studies[18,19,29]. These findings confirm that OLP patients have no increased prevalence with smoking or alcohol drinking abuse compared to the general population[44].

Results of the current study showed no significant association between the prevalence of types of LP (reticular, erosive, atrophic, plaque, bullous, and D. gingivitis) and category of age, gender, amalgam, smoking, alcohol, hypertension, and diabetes (all the $\mathrm{p}$ values were $>0.05$ ).

The differential diagnosis may include cheek chewing/frictional keratosis, leukoplakia, lupus erythematosus, pemphigus, mucous membrane pemphigoid, erythematous candidiasis, and chronic ulcerative stomatitis[24].

Histopathologically, epithelial dysplasia was present in four cases, two erosive and two atrophic types, which are similar to other study[45], which confirmed the diagnosis based on histopathological examination, while most of the studies reviewed in this paper have not mentioned confirmation of this condition by histopathological study, only based on clinical examination. Malignant transformation was not observed in the present study. These findings are consistent with studies by Murti et al. and Andreasen[45,46].

\section{Conclusions}

The present study revealed that many of the characteristics of OLP and OLR are in accordance with the previous study, except that all patients were free from $\mathrm{HCV}$ infection. The early diagnosis which must be confirmed by histopathological examination and long-term follow-up are necessary to evaluate their progress and any possible malignant transformation.

\section{Recommendations}

Our recommendations for future studies include:

1.Studies with a larger sample size and longer duration will be conducted all over Iraq to visualize the prevalence and 
distribution of OLP and OLR in Iraqi citizens.

2.More studies with a larger sample size and longer duration will be conducted to monitor the malignant transformation of OLP and OLR.

\section{References}

[1]Odell EW. Cawson's essentials of oral pathology and oral medicine. Elsevier Health Sciences; 2017 May 2; p: 261-262.

[2]Boorghani M, Gholizadeh N, Zenouz AT, Vatankhah M, Mehdipour M. Oral lichen planus: clinical features, etiology, treatment and management; a review of literature. Journal of dental research, dental clinics, dental prospects. 2010;4(1):3.

[3]Eulàlia Torrente-Castells, Rui Figueiredo, Leonardo Berini-Aytés, Cos $\neg m e$ GayEscoda. Clinical features of oral lichen planus. A retrospective study of 65 cases. Med Oral Patol Oral Cir Bucal. 2010;15:e685-90.

[4]Alves MG, Almeida JD, Balducci I, Cabral LA. Oral lichen planus: A retrospective study of 110 Brazilian patients. BMC research notes. 2010 Dec;3(1):157.

[5] 5. V. Kumar, A. Abbas, and J. Aster, Robbins \& Cotran Pathologic Basis of Disease, Saunders, Philadelphia, Pa, USA, 8th ed edition, 2009.

[6] 6. Sugerman P, Savage NW, Walsh LJ, Zhao ZZ, Zhou XJ, Khan A, Seymour GJ, Bigby M. The pathogenesis of oral lichen planus. Critical Reviews in Oral Biology \& Medicine. 2002 Jul;13(4):350-65.

[7]Scully C, Beyli M, Ferreiro MC, Ficarra G, Gill Y, Griffiths M, Holmstrup P, Mutlu S, Porter S, Wray D. Update on oral lichen planus: etiopathogenesis and management.
Critical Reviews in Oral Biology \& Medicine. 1998 Jan;9(1):86-122.

[8]Sugerman P, Savage NW, Walsh LJ, Zhao ZZ, Zhou XJ, Khan A, Seymour GJ, Bigby M. The pathogenesis of oral lichen planus. Critical Reviews in Oral Biology \& Medicine. 2002 Jul;13(4):350-65.

[9]Ismail SB, Kumar SK, Zain RB. Oral lichen planus and lichenoid reactions: etiopathogenesis, diagnosis, management and malignant transformation. Journal of oral science. 2007;49(2):89-106.

[10]Scully C, Carrozzo M. Oral mucosal disease: Lichen planus. British Journal of Oral and Maxillofacial Surgery. 2008 Jan 1;46(1):15-21.

[11]Neville BW, Damm DD, Allen CM, Bouquot JE. Oral and maxillofacial pathology, Saunders. St Louis. 2009:453-9. [12]Jahanshahi G, Aminzadeh A. A histochemical and immunohistochemical study of mast cells in differentiating oral lichen planus from oral lichenoid reactions. Quintessence International. 2010 Mar $1 ; 41(3)$.

[13]Issa Y, Brunton PA, Glenny AM, Duxbury AJ. Healing of oral lichenoid lesions after replacing amalgam restorations: a systematic review. Oral Surgery, Oral Medicine, Oral Pathology, Oral Radiology, and Endodontology. 2004 Nov 1;98(5):55365.

[14]Wray D, Rees SR, Gibson J, Forsyth A. The role of allergy in oral mucosal diseases. Qjm. 2000 Aug 1;93(8):507-11.

[15]Konidena A, Pavani BV. Hepatitis C virus infection in patients with oral lichen planus. Nigerian journal of clinical practice. 2011;14(2):228-31. 
[16]Oliveira Alves MG, Almeida JD, Guimarães Cabral LA. Association between hepatitis $\mathrm{C}$ virus and oral lichen planus: $\mathrm{HCV}$ and oral Lichen Planus. Hepat Mon. 2011;11:132-3.

[17]Payeras MR, Cherubini K, Figueiredo MA, Salum FG. Oral lichen planus: focus on etiopathogenesis. Archives of oral biology. 2013 Sep 1;58(9):1057-69.

[18]Pakfetrat A, Javadzadeh-Bolouri A, Basir-Shabestari S, Falaki F. Oral Lichen Planus: a retrospective study of 420 Iranian patients. Med Oral Patol Oral Cir Bucal. 2009;14:e315-8.

[19]Shen ZY, Liu W, Zhu LK, Feng JQ, Tang GY, Zhou ZT. A retro-spective clinicopathological study on oral lichen planus and malig $\neg$ nant transformation: Analysis of 518 cases. Med Oral Patol Oral Cir Bucal. 2012;17:e943-7.

[20]Ingafou M, Leao JC, Porter SR, Scully C: Oral lichen planus: a retrospective study of 690 British patients. Oral Dis. 2006;12: 463-8.

[21]Scully C. Oral and maxillofacial medicine; the basis of diagnosis and treatment. 3rd. ed. London, UK: Elsevier Ltd. 2013; P. 138.

[22]Eisen D. The evaluation of cutaneous, genital, scalp, nail,esophageal, and ocular involvement in patients with oral lichen planus. Oral Surg Oral Med Oral Pathol Oral Radiol Endod 1999;88:431-6.

[23]Shi P, Liu W, Zhou ZT, He QB, Jiang WW. Podoplanin and ABCG2: Malignant transformation risk markers for oral lichen planus. Cancer Epidemiol Biomarkers Prev 2010;19:844-9.
[24]Lavanya N， Jayanthi P, Rao UK, Ranganathan K. Oral lichen pla $\neg n u s:$ An update on pathogenesis and treatment. J Oral Maxillofac Pathol. 2011;15:127-32. [25]Van der Meij EH, Schepman KP, van der Waal I. The possible premalignant character of oral lichen planus and oral lichenoid lesions: A prospective study. Oral Surg Oral Med Oral Pathol Oral Radiol Endod 2003;96:164-71.

[26]Bermejo-Fenoll A, Sanchez-Siles M, Lopez-Jornet P, Camacho-Alonso F, Salazar -Sanchez N. A retrospective clinicopathological study of 550 patients with oral lichen planus in south-eastern Spain. J Oral Pathol Med 2010;39:491-6.

[27]Xue JL, Fan MW, Wang SZ, Chen XM, Li Y, Wang L. A clinical study of 674 patients with oral lichen planus in China. $\mathrm{J}$ Oral Pathol Med 2005;34:467-72.

[28]Carbone M, Arduino PG, Carrozzo M, Gandolfo S, Argiolas MR, Bertolusso G, et al. Course of oral lichen planus: a retrospective study of 808 northern Italian patients. Oral Dis. 2009;15:235-43.

[29]Bermejo-Fenoll A, Sanchez-Siles M, López-Jornet P, Camacho-Alonso F, SalazarSanchez N. Premalignant nature of oral lichen planus. A retrospective study of 550 oral lichen planus patients from south-eastern Spain. Oral Oncol. 2009;45:e54-6.

[30] Pindborg JJ, Mehta FS, Daftary DK, Gupta PC, Bhonsle RB. Prevalence of oral lichen planus among 7639 Indian villagers in Ker $\neg$ ala, South India. Acta Derm Venereol. 1972;52:216-20.

[31]Bouquot JE, Gorlin RJ. Leukoplakia, lichen planus, and other oral keratoses in 
23,616 white Americans over the age of 35 years. Oral Surg Oral Med Oral Pathol. 1986;61:373-81.

[32]Tovaru S, Parlatescu I, Gheorghe C, Tovaru M, Costache M, Sarde $\neg$ lla A. Oral lichen planus: A retrospective study of 633 patients from Bucharest, Romania. Med Oral Patol Oral Cir Bucal. 2013;18:e201-6.

[33] Ingafou M, Leao JC, Porter SR, Scully

C. Oral lichen planus: a retrospective study of 690 British patients. Oral Dis. 2006;12:463-9.

[34]Torrente-Castells E, Figueiredo R, Berini-Aytés L, Gay-Escoda C. Clinical features of oral lichen planus. A retrospective study of 65 ca $\neg$ ses. Med Oral Patol Oral Cir Bucal. 2010;15:e685-90.

[35]Munde AD, Karle RR, Wankhede PK, Shaikh SS, Kulkurni M. Demographic and clinical profile of oral lichen planus: A retrospective study. Contemporary clinical dentistry. 2013 Apr;4(2):181.

[36]Gorsky M, Raviv M, Moskona D, Laufer M, Bodner L. Clinical characteristics and treatment of patients with oral lichen planus in Israel. Oral Surgery, Oral Medicine, Oral Pathology, Oral Radiology, and Endodontology. 1996 Dec 1;82(6):644-9.

[37]Hietanen J, Paasonen MR, Kuhlefelt M, Malmström M. A retrospective study of oral lichen planus patients with concurrent or subsequent development of malignancy. Oral oncology. 1999 May 1;35(3):278-82.

[38]Edwards PC, Kelsch R. Oral lichen planus: Clinical presentation and management. J Can Dent Assoc 2002;68:494 -9 .

[39]Lauritano D, Arrica M, Lucchese A, Valente M, Pannone G, Lajolo C et al. Oral lichen planus clinical characteristics in Italian patients: a retrospective analysis. Head Face Med. 2016;12:18.

[40]Pezelj-Ribarić S, Prpić J, Miletić I, Brumini G, Šoškić MŠ, Anić I. Association between oral lichenoid reactions and amalgam restorations. Journal of the European Academy of Dermatology and Venereology. 2008 Oct;22(10):1163-7.

[41]Duxbury AJ, Ead RD, McMurrough S, Watts DC. Allergy to mercury in dental amalgam. British dental journal. 1982 Jan $19 ; 152(2): 47$.

[42]Chainani-Wu N, Silverman S, Jr, Lozada-Nur F, Mayer P, Watson JJ. Oral lichen planus: Patient profile, disease progression and treatment responses. J Am Dent Assoc. 2001; 132 : 901-9.

[43]Lodi G, Giuliani M, Majorana A, Sardella A, Bez C, Demarosi F, et al. Lichen planus and hepatatis $\mathrm{C}$ virus: a multicentric study of patients with oral lesions and a systematic review. $\mathrm{Br} \mathrm{J}$ Dermatol. 2004;151:1172-81.

[44]Eisen D. The clinical features, malignant potential, and systemic associations of oral lichen planus: a study of 723 patients. J Am Acad Dermatol. 2002;46:207-14.

[45]Murti PR, Daftary DK, Bhonsle RB, Gupta PC, Mehta FS, Pindborg JJ. Malignant potential of oral lichen planus: Observations in 722 patients from India. J Oral Pathol 1986;15:71-7.

[46]Andreasen JO. Oral lichen planus. 1. A clinical evaluation of 115 cases. Oral Surg Oral Med Oral Pathol 1968;25:31-42. 